\title{
Design Of A Mems Device For Studying Cell Migration And Differentiation
}

\author{
Ivan Torres ${ }^{1}$, Luci Eland ${ }^{2}$, Christopher Redfern ${ }^{3}$ and John Hedley ${ }^{l}$ \\ School of Engineering ${ }^{1}$ \\ The Centre for Bacterial Cell Biology ${ }^{2}$ \\ Northern Institute of Cancer Research ${ }^{3}$ \\ Newcastle University \\ Newcastle upon Tyne, NE1 7RU, UK \\ Email: i.torres@ncl.ac.uk
}

\begin{abstract}
The aim of this project is to develop a novel device, using a micro force sensing array, which can be used to study forces involved in cell migration and the cellular responses to drugs that may inhibit migration or induce differentiation. The system was modelled with an optimum geometry of $1 \mu \mathrm{m}$ diameter and $10 \mu \mathrm{m}$ length for forces down to 1 nanometre. Devices were fabricated using conventional photolithography and reactive ion etching techniques. To demonstrate proof of principle cells were successfully grown on the devices.
\end{abstract}

Keywords-biosensor; metastasis; mechanotransduction; micropillar; micro force sensing array; PDMS; drug analysis

\section{INTRODUCTION}

Nowadays, cancer early detection has been intensely studied before it spreads throughout the body, a process called metastasis. Current techniques for cancerous cell detection, such as immunofluorescence analysis, focus in shape recognition in which the shape of cancerous cells (rounded) are different to that of healthy cells (large and flat). However cancerous cells may mimic shape of healthy cells and therefore such a test might provide a false positive error. Consequently, techniques are needed to discriminate cells [1].

Previous studies [1-4] demonstrated that healthy cells can be differentiated from cancerous cells by measuring their mechanical and electrical properties. Due to the size of the cells microelectromechanical systems (MEMS) have been intensely used for this purpose. For instance, a previous study [1] found that cancerous cells are $70 \%$ softer than healthy cells. Some of these mechanical techniques potentially provide erroneous results due to the presence of artefacts created by the external loads exerted onto the cells. Therefore, non-contact methods [2,5-11] such as chemical, electrical and optical means are used. Optical methods are preferred because chemical methods may affect the cell chemistry while electrical methods need to work under specific conditions [2]. Previously reported studies using optical methods look at the cell migration response via mechanical cues, known as mechanotransduction, and measure rigidity [14-20], topography [9, 13] and geometry [6-8, 12, 2123]. Micro force sensing arrays $(\mu F S A)$ provide a powerful tool to study mechanotransduction. These arrays consist of micropillars where forces involved in cell migration deflect these pillars. These deflections can be measured with a light microscope and analysed to calculate the applied force. Some of the advantages of these devices are high sensitivity to measure forces down to 0.1 nanonewton $(\mathrm{nN})$, simple design, and each pillar is independent from the neighbour thereby allowing the measure of local forces [6-8, 12, 21-23].

The aim of this work is to model a micropillar geometry allowing for a force measurement resolution of $1 \mathrm{nN}$, establish a reliable manufacturing procedure for the fabrication of the arrays and determine the protocols for cell growth onto these devices.

\section{MODELLING AND MATHEMATICAL FORMULATION}

Micro force sensing arrays are often fabricated from silicon or polydimethylsiloxane (PDMS). Typically PDMS is preferred over silicon as it has a Young's modulus $10^{4}$ times lower than silicon providing a lower spring constant in order to detect nanonewton forces. This allows an easy, rapid fabrication and convenient low aspect ratio designs for a given required stiffness [6].

Two crucial dimensions in microarray design are pillar radius, which has to be small enough to accommodate one focal adhesion on each pillar and big enough to successfully contain all the contact area of the individual focal adhesion, and space between pillars, which should be small enough to avoid anchoring of the cell between pillars. Previous studies demonstrated that the minimal required radius is 1 micrometre ( $\mu \mathrm{m})$ with micropillar spacing of $2 \mu \mathrm{m}[6,13]$. As a cell migrates it causes deflections in the micropillars which can be calculated by the Euler-Bernoulli beam theory equation, see (1) [6]:

$$
\mathrm{F}=\mathrm{kx}=\left(\frac{3}{4} \pi \mathrm{E} \frac{\mathrm{r}^{4}}{\mathrm{~L}^{3}}\right) \mathrm{x}
$$

where $\mathrm{k}$ is the stiffness, $\mathrm{x}$ the pillar deflection, E the Young's modulus, $r$ the pillar radius and $L$ the length of the pillar.

For modelling purposes, deflection is theoretical calculated using (1). With a cell force measurement resolution of $1 \mathrm{nN}$ being required, a perpendicular force of $1 \mathrm{nN}$ was applied to a 
micropillar with $1 \mu \mathrm{m}$ radius whilst the Young modulus and length varied, see Fig.1. Due to resolution of conventional light microscopes, it is aimed to measure deflections of $0.2 \mu \mathrm{m}$. Finite element analysis (FEA) was performed and showed good agreement with the analytical prediction, see Fig.2. It was found that the optimal pillar characteristics are: $1 \mu \mathrm{m}$ radius, $10 \mu \mathrm{m}$ length with a Young's modulus of $2 \mathrm{MPa}$.

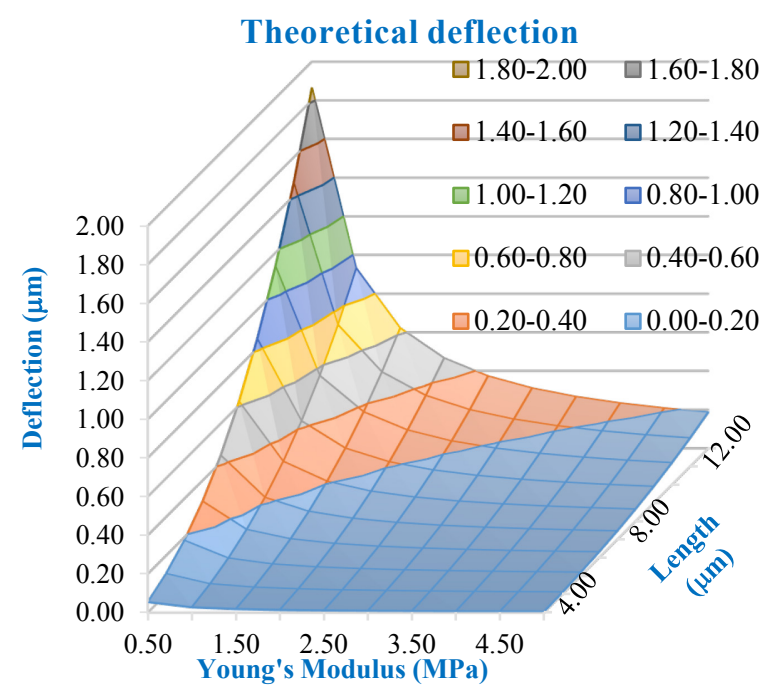

Fig. 1. Theroterical deflection for given micropillar length and Young's modulus.

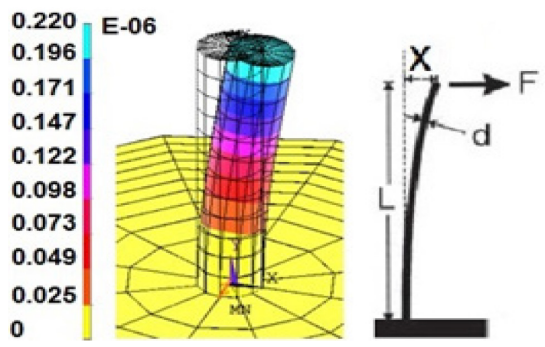

Fig. 2. FEA of micropillar. For model shown, $\mathrm{D}=2 \mu \mathrm{m}, \mathrm{L}=10 \mu \mathrm{m}, \mathrm{F}=1 \mathrm{nN}$.

\section{FABRICATION}

\section{A. Silicon mould fabrication}

Firstly, a photoresist layer was deposited onto a silicon wafer. UV light exposed through a photomask created the desired micropillar pattern. The exposed silicon area was etched $10 \mu \mathrm{m}$ using reactive ion etching and then the photoresist was removed. Finally, the silicon wafer was diced into chips of $10 \times 10 \mathrm{~mm}$. A cross sectional view of a fabricated die is shown in Fig.3.

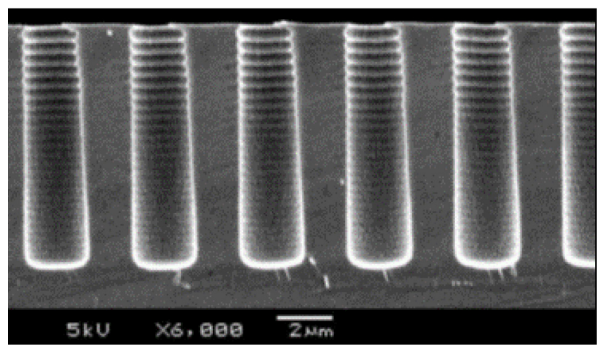

Fig. 3. SEM image. Cross-sectional area of silicon chips

\section{B. Silanization}

One of the major problems of working with PDMS is stiction that leads to difficulties during peel off. As shown in Fig.4, micropillars can fracture and break at the micropillar base due to the stiction between the PDMS pillars walls and the silicon wafer.

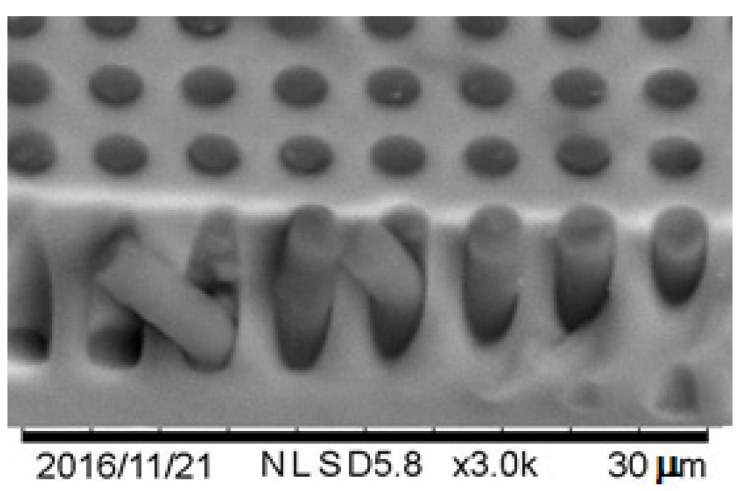

Fig. 4. Cross-section showing PDMS incrusted in the silicon wafer.

Therefore silanization is required on the silicon wafers. This makes the silicon wafer surface hydrophobic and reduces this stiction effect. For silanization, dies were rinsed with isopropanol and then dried with $\mathrm{N}_{2}$. Next, $40 \mu \mathrm{L}$ of $1 \mathrm{H}, 1 \mathrm{H}, 2 \mathrm{H}$, $2 \mathrm{H}$-Perfluorooctyltrichlorosilane solution was placed on a lens cleaning tissue and then placed in a vacuum desiccator along with the dies. Finally, a vacuum was applied and the dies were allowed to incubate for 30 minutes.

\section{Micropillarfabrication}

PDMS, type SYLGARD 184, was prepared with 1:10 curing-base ratio in a glass beaker. The mixture was placed in a desiccator and a vacuum applied for 1 hour to eliminate any air trapped in the mixture. The PDMS was then poured into a petri dish containing the silicon dies. A vacuum was reapplied for 1 hour. The PDMS was cured in an oven at $60^{\circ} \mathrm{C}$ for 18 hours. The fully cured PDMS was peeled off under $70 \%$ ethanol to avoid the pillars sticking with each other.

\section{Critical point drying (CPD)}

One of the drawbacks of peeling off under a solution is the resulting congregation of pillars due to the surface tension of the solution as it evaporates. This causes the pillars to stick with their neighbours as seen in Fig.5. Therefore, critical point drying (CPD) was performed to alleviate this issue.

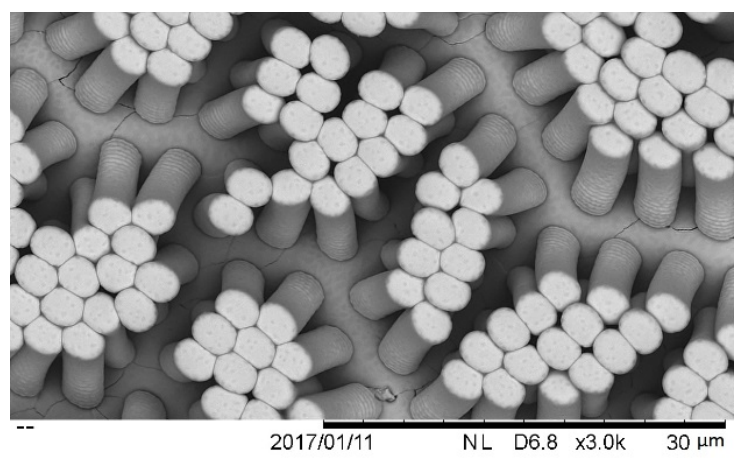

Fig. 5. SEM image showing PDMS pillar collapse due to surface tension forces. 
SEM images of the finally fabricated PDMS micropillars are shown in Fig.6 and demonstrated the suitability of the final process flow for micropillar fabrication.

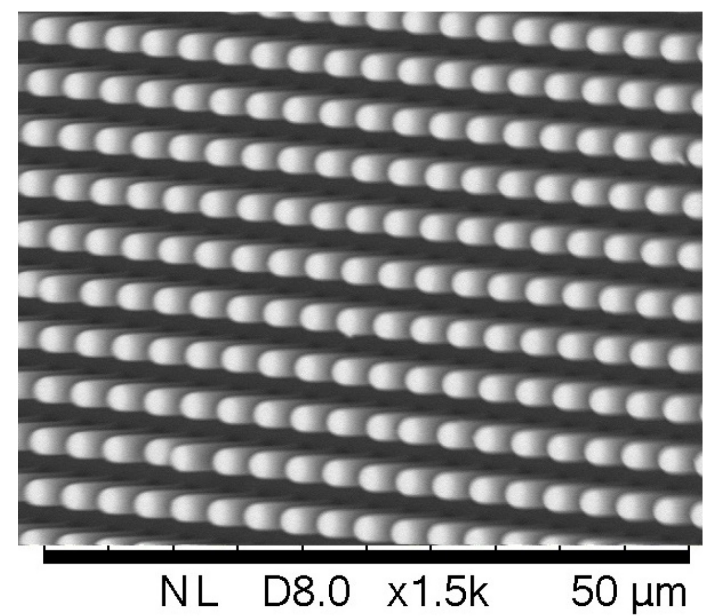

Fig. 6. SEM image, taken at $45^{\circ}$, of PDMS pillars.

\section{E. Cell seeding}

Cancerous cells, obtained from the A549 cell line at the Northern Institute of Cancer Research (NICR), were successfully cultivated on the devices as proof of principle, see Fig.7. Cultivation was done in RPMI 1640 medium containing $10 \%$ foetal bovine serum (FBS). Cells were maintained between $1 \times 10^{5}$ and $1 \times 10^{6}$ cells $/ \mathrm{ml}$ and incubated with $5 \% \mathrm{CO}_{2}$ at $37^{\circ} \mathrm{C}$ for 2 days.

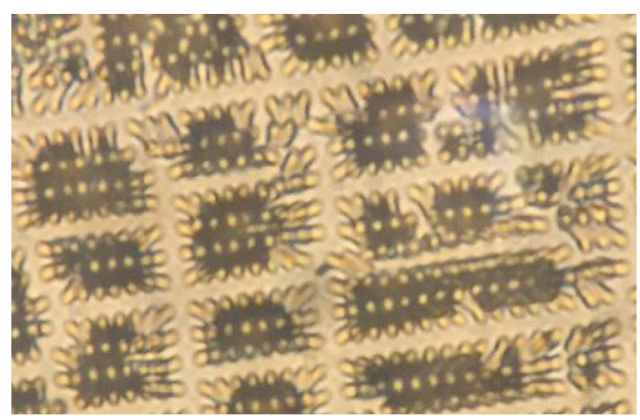

Fig. 7. Example of cell cultivation on array of PDMS. 40x light microscope image.

\section{CONCLUSION}

For a $1 \mathrm{nN}$ force resolution, it was found that the optimal characteristics for micropillars are $1 \mu \mathrm{m}$ radius, $10 \mu \mathrm{m}$ length with a Young's modulus of $2 \mathrm{MPa}$. Standard microfabrication was used to create the mould template. Silanization and CPD were required to facilitate succesful PDMS array production. Cells were succesfully incubated on the device as proof of principle. The next stage of the work is to monitor cell propagation in real time and record micropillar deflection.

\section{REFERENCES}

[1] S. E. Cross, Y.-S. Jin, J. Rao et al., "Nanomechanical analysis of cells from cancer patients," Nature nanotechnology, vol. 2, no. 12, pp. 780783, 2007.
[2] C. Dalmay, A. Pothier, M. Cheray et al., "On-chip biosensors based on microwave detection for cell scale investigations," Biomedical Engineering Systems and Technologies, pp. 51-63: Springer, 2010.

[3] N. Scuor, P. Gallina, H. V. Panchawagh et al., "Design of a novel MEMS platform for the biaxial stimulation of living cells," Biomedical microdevices, vol. 8, no. 3, pp. 239-246, 2006.

[4] K. D. Costa, A. J. Sim, and F. C. P. Yin, "Non-Hertzian Approach to Analyzing Mechanical Properties of Endothelial Cells Probed by Atomic Force Microscopy," Journal of Biomechanical Engineering, vol. 128, no. 2, pp. 176-184, 2005.

[5] R. Swierczewski, J. Vazquez, J. Hedley et al., "Microsystem for Real Time High Resolution Measurement of Cell Forces," Sensors Journal, IEEE, vol. 13, no. 5, pp. 1602-1609, 2013.

[6] M. Gupta, L. Kocgozlu, B. R. Sarangi et al., "Micropillar substrates: A tool for studying cell mechanobiology," Methods in cell biology, vol. 125, pp. 289-308, 2015.

[7] O. Du Roure, A. Saez, A. Buguin et al., "Force mapping in epithelial cell migration," Proceedings of the National Academy of Sciences of the United States of America, vol. 102, no. 7, pp. 2390-2395, 2005.

[8] J. Le Digabel, M. Ghibaudo, L. Trichet et al., "Microfabricated substrates as a tool to study cell mechanotransduction," Medical \& biological engineering \& computing, vol. 48, no. 10, pp. 965-976, 2010.

[9] K. O. Okeyo, H. Miyoshi, and T. Adachi, Innovative Approaches to Cell Biomechanics: Springer, 2015.

[10] R. Ananthakrishnan, and A. Ehrlicher, "The forces behind cell movement," International journal of biological sciences, vol. 3, no. 5, pp. 303, 2007.

[11] D. A. Lauffenburger, and A. F. Horwitz, "Cell migration: a physically integrated molecular process," Cell, vol. 84, no. 3, pp. 359-369, 1996.

[12] M. Ghibaudo, A. Saez, L. Trichet et al., "Traction forces and rigidity sensing regulate cell functions," Soft Matter, vol. 4, no. 9, pp. 1836-1843, 2008

[13] M. Ghibaudo, L. Trichet, J. Le Digabel et al., "Substrate Topography Induces a Crossover from 2D to 3D Behavior in Fibroblast Migration," Biophysical Journal, vol. 97, no. 1, pp. 357-368, 7/8/, 2009.

[14] A. T. Higa, "Cellular mechanotransduction via microfabricated post arrays," University of California, Berkeley, 2012.

[15] C.-M. Lo, H.-B. Wang, M. Dembo et al., "Cell movement is guided by the rigidity of the substrate," Biophysical journal, vol. 79, no. 1, pp. 144$152,2000$.

[16] N. Zaari, P. Rajagopalan, S. K. Kim et al., "Photopolymerization in microfluidic gradient generators: microscale control of substrate compliance to manipulate cell response," Advanced Materials, vol. 16, no. 23 - 24, pp. 2133-2137, 2004.

[17] J. A. Burdick, A. Khademhosseini, and R. Langer, "Fabrication of gradient hydrogels using a microfluidics/photopolymerization process," Langmuir, vol. 20, no. 13, pp. 5153-5156, 2004.

[18] J. Y. Wong, A. Velasco, P. Rajagopalan et al., "Directed movement of vascular smooth muscle cells on gradient-compliant hydrogels," Langmuir, vol. 19, no. 5, pp. 1908-1913, 2003.

[19] D. S. Gray, J. Tien, and C. S. Chen, "Repositioning of cells by mechanotaxis on surfaces with micropatterned Young's modulus," Journal of Biomedical Materials Research Part A, vol. 66, no. 3, pp. 605614, 2003.

[20] S. Kidoaki, and T. Matsuda, "Microelastic gradient gelatinous gels to induce cellular mechanotaxis," Journal of biotechnology, vol. 133, no. 2, pp. 225-230, 2008.

[21] A. Jasaitis, M. Estevez, J. Heysch et al., "E-cadherin-dependent stimulation of traction force at focal adhesions via the Src and PI3K signaling pathways," Biophysical journal, vol. 103, no. 2, pp. 175-184, 2012.

[22] J. L. Tan, J. Tien, D. M. Pirone et al., "Cells lying on a bed of microneedles: an approach to isolate mechanical force," Proceedings of the National Academy of Sciences, vol. 100, no. 4, pp. 1484-1489, 2003.

[23] A. Saez, E. Anon, M. Ghibaudo et al., "Traction forces exerted by epithelial cell sheets," Journal of Physics: Condensed Matter, vol. 22, no. 19, pp. 194119, 2010. 